\title{
REFINING OF BAMBOO LONG FIBER FRACTION PULP: EFFECTS ON WET WEB AND DRY STRENGTH PROPERTIES OF PAPER
}

\author{
NISHI K. BHARDWAJ \\ Avantha Centre for Industrial Research and Development, Paper Mill Campus, \\ Yamuna Nagar 135001, Haryana, India \\ × Corresponding author: bhardwaj@avantharesearch.org
}

Received June 19, 2018

\begin{abstract}
Papermakers are encouraged to use non-wood fibers for a variety of reasons although there is less knowledge on how to treat non-wood fibers. The papermaking process, machine runnability and paper quality are significantly affected by the mechanical treatment of fibers known as beating or refining of pulp. Paper machines with higher production rates tend to have higher downtime because of paper breaking. Energy savings and the desired paper properties can be obtained by choosing appropriate refining process conditions. The laboratory studies reported here aimed at understanding the behavior of unbleached bamboo long fiber fraction pulp upon refining in an Escher Wyss Laborefiner under simulated process conditions, which included the investigation of important parameters, such as wet web tensile, wet web elongation, water retention value and paper strength properties. The paper describes the influence of two specific edge loads, 1000 and $1500 \mathrm{Ws} / \mathrm{km}$, on pulp refining. Bamboo long fiber fraction pulp responds better to lower intensity refining, in terms of pulp strength.
\end{abstract}

Keywords: bamboo pulp, long fiber, refining, wet web strength, water retention value, dry strength

\section{INTRODUCTION}

Wood pulps are commonly used for papermaking in countries where wood is plentifully available, whereas non-wood pulps are widely used in other countries, such as China, India and many other Asian, East European, Middle East and African countries, with limited forest resources and abundant availability of agricultural residues and non-wood plants. Nonwood fibers differ from wood fibers in their structure, morphology and chemical composition. Bamboo, a rapidly grown agricultural crop from the family of grasses, has several advantageous qualities, which give it great potential as an alternative fiber resource for the pulp and paper industry. It yields a long fibered pulp that forms paper of good mechanical strength, compared to the paper made from softwood pulp. For this reason, bamboo has received increasing attention as a unique raw material and its chemical pulp is also used as reinforcement pulp in some countries. The high strength of bamboo pulps, in comparison with the majority of other non-wood pulps, makes them a prospective raw material to be used for producing more versatile paper grades. India has good resources of bamboo, with
130 species covering about $96,000 \mathrm{~km}^{2}$ or about $13 \%$ of the total forest area. ${ }^{1}$

The original quality and strength of fibers, as well as the bonding among them, affect the strength properties of paper. Paper made from unbeaten or unrefined fibers exhibits low bulk, low strength and rough surface, which are generally undesirable for different end uses. These characteristics can be improved significantly by mechanical treatment of fibers, a process known as beating/refining. Among different papermaking processes, the refining of pulp is a complex and the most influential process, linking the fiber manufacturing processes to the paper manufacture processes as shown below:

Chemical pulp $\longrightarrow$ refining $\longrightarrow$ paper machine

The mechanical treatment of chemical pulps was reviewed earlier. ${ }^{2}$ The structural changes in the fibers, ascribed to beating or refining, are fiber swelling/shortening/fibrillation.,

Beating/refining improves not only fiber properties, but also paper properties. Apart from 
affecting the quality of the end product, the refining of pulp also influences the papermaking process by affecting the wet runnability of the stock, which is mainly dependent on the performability of the treated furnish due to fiber quality improvements after refining. High tensile and tear strengths are desirable for good runnability. Energy savings and the desired paper properties can be obtained by applying appropriate refining process conditions and bad refining cannot be compensated in the subsequent processing steps. Beating/refining imparts three main effects: internal fibrillation, facilitating flexibility and conformability of fibers during sheet formation; the creation/exposure of fibrils, known as external fibrillation; and fines generation from fibers due to mechanical treatment. $^{5}$

Due to refining and generation of fibrils, the water holding capacity of the fibers is increased, so that it is difficult to dewater the refined pulp. The degree of bonding between fibers is increased due to an increase in flexibility, specific surface area and fiber collapsibility. The refining process conditions have to be selected so that they maximize the desirable effects and minimize the undesirable effects. ${ }^{6}$

In the refining sector, there are several theoretical methods for assessing the results. Many of these are based on the theoretical model developed previously ${ }^{7,8}$ for practical assessment of refining results. The use of a specific edge load to give a quantified pulp evaluation is well documented and was pioneered by J. E. Levlin. ${ }^{9}$ The specific edge load measures the severity of the process, whereas the specific net energy in refining is related to the number of impacts. The refining process can be described by the following equations:

$\mathrm{B}_{\mathrm{s}}=\mathrm{P}_{\mathrm{n}} / \mathrm{L}_{\mathrm{s}}$

$\mathrm{W}_{\mathrm{e}}=\mathrm{P}_{\mathrm{n}} / \mathrm{m}$

where $B_{s}$ is the specific edge load (Ws $/ m$ ), $P_{n}$ is the net power $(\mathrm{kW})$, i.e. operating power minus no load power, $\mathrm{L}_{\mathrm{s}}$ is the cutting edge length $(\mathrm{km} / \mathrm{s}), \mathrm{W}_{\mathrm{e}}$ is the specific net energy $(\mathrm{kWh} / \mathrm{t})$, and $\mathrm{m}$ is the dry fiber flow $(\mathrm{t} / \mathrm{h})$.

These formulae are quite useful for comparing different alternatives for pulp refining. Considerable work has been done on understanding the effects of various refining parameters on wood pulp, but the refining behavior of non-wood pulps is not much understood. Non-wood fibers are generally short, slender and accompanied by a high proportion of non-fibrous elements. ${ }^{10}$ The complex nature of the non-wood fiber pulps poses greater challenges to the refining process.

Some works have dealt with refining of bamboo pulp and their potential in manufacturing fine papers. ${ }^{11-21}$ Several studies have been published regarding the mechanical and wet web properties of various furnishes and paper machine runnability. Some studies imply that for paper machine effectiveness, the wet web strength is one of the most important parameters. ${ }^{22-31}$ However, no study has explicitly aimed to investigate wet web and dry strength properties of unbleached bamboo long fiber fraction pulp upon refining in an Escher Wyss Laborefiner. Bamboo pulp consists not only of fibers, but also of a number of other elements, such as parenchyma cells, vessel elements and epidermal cells. Bamboo pulp contains about $70 \%$ fibers, and can be considered at par with softwood in terms of strength development. Bamboo pulp is used in India for producing high quality writing and printing papers, as well as for long fiber furnish in newsprint made of hardwood pulp. The choice of bamboo long fiber fraction pulp for this study was largely due to the fact that the changing raw material situation has compelled a number of mills to try bamboo long fiber fraction pulp as a substitute for softwood pulp to reduce the frequency of paper web breaks during manufacturing. It has become necessary to obtain relevant information with regard to the behavior of such pulp to refining, which is of vital importance to achieve good runnability and production on the paper machine.

The aim of the present study is to understand the behavior of unbleached bamboo long fiber fraction pulp upon refining in an Escher Wyss Laborefiner under simulated process conditions. The Escher Wyss is recognized as being able to simulate mill type refiners ${ }^{9}$ though the PFI mill continues to be the most commonly used laboratory refining device. ${ }^{32}$ In the present study, experiments have been conducted to understand the effects of specific edge loads on the development of wet web properties and dry strength properties during refining of bamboo long fiber fraction pulp.

\section{EXPERIMENTAL}

\section{Pulp sample}

Before refining, air-dried unbleached bamboo long fiber fraction pulp was slushed for 10 minutes in 25 
liters of water to obtain $4 \%$ pulp consistency (defined as the ratio of the dry weight of pulp fibers to the weight of the pulp suspension, expressed as percentage). Pulp freeness was measured as Canadian Standard Freeness, using standard Tappi test method T 227 om-99. The freeness, which was mainly influenced by fiber fibrillation and the amount of fine elements, was $660 \mathrm{~mL}$ CSF for the unrefined pulp.

\section{Refining of pulp}

The pulp samples were refined in an Escher Wyss laboratory refiner. No load power was determined by feeding water through the refiner at the open refining gap position by operating the calibration routine, just prior to each experiment. The refining experiments with pulp were carried out under the general conditions that were used in the calibration. The following general conditions were used in all the experiments: disc refiner - single disc refiner; disc pattern - 3-1.12-60; disc diameter - 6 inches; RPM - 2000; peripheral speed - $943 \mathrm{~m} / \mathrm{min}$; edge length - $1.12 \mathrm{~km} / \mathrm{s}$; specific edge load - 1000 or $1500 \mathrm{Ws} / \mathrm{km}$; pulp consistency 4\%. Each experiment was carried out using normally $1000 \mathrm{~g}$ pulp (on dry basis).

\section{Measurement of wet web strength}

After freeness determination, the pulps were further diluted to $0.18 \%$ consistency and wet web strips measuring $20 \mathrm{~mm}$ in width and $150 \mathrm{~mm}$ in length were made by placing a stainless steel mould on top of the wire mesh of a British sheet making machine during handsheet preparation. After removal of the mould, the wet strips were covered by blotting paper and pressed by placing a steel plate and $3 \mathrm{~kg}$ weight for 40 to 60 seconds on top of the blotting paper before transferring strips onto the blotter. For getting a wider range of dryness values, these strips were subjected to further pressing, changing the blotters, to absorb the water from the wet strips. After pressing, the strips were tested for wet web tensile index and elongation, using a Lorentzen \& Wettre wet web strength tester as per SCAN C:31:77 method. The dryness values of the tested strips were determined subsequently. The oven dry grammage of the strips was $100 \pm 5 \mathrm{~g} / \mathrm{m}^{2}$. The wet web tensile strength is the maximum tensile force per unit width that a wet web test piece stands before breaking in a tensile test. The wet web tensile strength divided by the grammage (oven dry basis) of the test piece gives the wet web tensile index. Instead of reporting the wet web properties at $25 \%$ dryness, as required by the SCAN method, the wet web properties are reported at $20 \%$ dryness as this condition is more appropriate for the open draw machines widely used in India.

\section{Measurement of water retention value}

Water retention values were determined using a centrifuge equipped with steel tubes, capable of attaining a speed of $6000 \mathrm{rpm}$. Each tube was $5.5 \mathrm{~cm}$ in diameter and was fitted with a short inner sleeve for holding a coarse grid supporting a 100 mesh screen about $4 \mathrm{~cm}$ above the bottom of the tube. To start an experimental run, samples of moist pulp, weighing the equivalent to $1 \mathrm{~g}$ oven dry weight, were placed on the screens and centrifuged at $5500 \mathrm{rpm}$ for 10 minutes to reach a force of $3000 \mathrm{~g}$. The pulp samples that were still moist were taken out and immediately weighed. These were then dried in an oven at $105{ }^{\circ} \mathrm{C}$ and their moisture content was determined. From this value, the water retained by the pulp after centrifuging, as percentage of the oven dry fiber, was taken as the water retention value.

\section{Dry strength evaluation}

Handsheets of $60 \mathrm{gsm}$ were made on a British sheet former as per ISO 5269-1: 2005. The standard handsheets were conditioned at $27 \pm 1{ }^{\circ} \mathrm{C}$ and $65 \pm 2 \%$ relative humidity, Indian standard atmospheric conditions, following IS/ISO 187:1990. The following tests on dry strength properties were determined using standard ISO methods: (i) Thickness, ISO 534:1988 (E); (ii) Tensile strength index ISO 1924-2: 1994 (E); (iii) Burst strength index, ISO 2758; (iv) Tearing strength index, ISO 1974: 1994 (E).

\section{RESULTS AND DISCUSSION}

Bamboo long fiber fraction pulp at $4 \%$ consistency was refined at two specific edge loads, 1000 and $1500 \mathrm{Ws} / \mathrm{km}$, to different freeness levels in the range from 660 to $105 \mathrm{~mL} \mathrm{CSF}$. The refined pulp samples were collected at the net specific energy levels ranging from 0 to 290 $\mathrm{kWh} / \mathrm{t}$. Subsequently, the wet web and dry strength properties of the bamboo long fiber fraction pulp were measured. The water retention value related to the swelling of the pulp was used as an indicator of the bonding properties of the pulp.

The refining process strengthens the interactions that develop between cellulose fibers as the paper is dried and thus paper of sufficient quality can be produced from refined cellulosic pulp. ${ }^{33}$ The results discussed below are results obtained for dried and rewetted pulp. The strength properties of undried virgin pulp will be superior to those of dried and rewetted pulp, ${ }^{34}$ while the properties of paper made on a paper machine would be similar to those of handsheets made in the laboratory under similar refining conditions.

The freeness tests are commonly used to measure the effects of refining in an indirect way. In the paper making process, high drainage is preferable, while the reduction in dewatering of the pulp caused by refining, as measured by freeness, is not desirable. The evolution of 
freeness with refining at different specific edge loads is plotted against the net specific energy in Figure 1. As expected, the freeness decreased with an increase in refining energy. It is observed from the data that, mostly, the drop in freeness for the pulp refined at $1000 \mathrm{Ws} / \mathrm{km}$ specific edge load is higher, compared to that of the pulp refined at $1500 \mathrm{Ws} / \mathrm{km}$ specific edge load at the given net specific energy levels. The freeness can be mainly affected by the degree of fibrillation and the level of fines. This indicates that the refining action at $1500 \mathrm{Ws} / \mathrm{km}$ specific edge load, compared to refining at $1000 \mathrm{Ws} / \mathrm{km}$ specific edge load, results in a lower degree of fibrillation and a lower level of fines. The freeness test provides a convenient measure of the level of fibrillation, so that the higher the degree of fibrillation, the lower the freeness. ${ }^{35}$

\section{Comparison of wet web properties}

Refining increased the wet web tensile strength, wet web elongation both at $20 \%$ dryness and water retention value of the pulp. Both wet web tensile and wet web elongation increase upon refining due to increased fiber-fiber interaction. The wet web tensile index of the pulp refined at $1000 \mathrm{Ws} / \mathrm{km}$ specific edge load, at any net specific energy level, was comparatively higher than that of the pulp refined at $1500 \mathrm{Ws} / \mathrm{km}$ specific edge load (Fig. 2). Lower intensity refining increased net energy efficiency. From Figure 2, it can be seen that by applying 110 $\mathrm{kWh} / \mathrm{t}$ net specific energy at $1500 \mathrm{Ws} / \mathrm{km}$ specific edge load, a wet web tensile index of $0.90 \mathrm{Nm} / \mathrm{g}$ was developed, whereas for the specific edge load of $1000 \mathrm{Ws} / \mathrm{km}$ at a net specific energy level of $95 \mathrm{kWh} / \mathrm{t}$ only, the wet web tensile index was higher - of $1.15 \mathrm{Nm} / \mathrm{g}$. At the two SELs studied, there is a huge difference $(110 \mathrm{kWh} / \mathrm{t})$ in the specific energy required to reach a given wet web tensile index, $1.2 \mathrm{Nm} / \mathrm{g}$, about $210 \mathrm{kWh} / \mathrm{t}$ for $1500 \mathrm{Ws} / \mathrm{km}$, compared with around $110 \mathrm{kWh} / \mathrm{t}$ for $1000 \mathrm{Ws} / \mathrm{km}$.

The wet web elongation is measured as the ratio of the increase in length of a test piece at the time when the maximum tensile force is reached during a tensile test of wet web to the initial test length. The ability of the wet web to redistribute the stress is related to the elongation of the wet web. The results of the measurement of wet web elongation at $20 \%$ dryness are plotted in Figure 3. The wet web elongation of the pulp refined at $1000 \mathrm{Ws} / \mathrm{km}$ specific edge load, compared to that refined at $1500 \mathrm{Ws} / \mathrm{km}$ specific edge load, was lower at the initial stages of refining, and subsequently improved with refining. In the early phases of refining, the higher specific edge load appears to be beneficial.

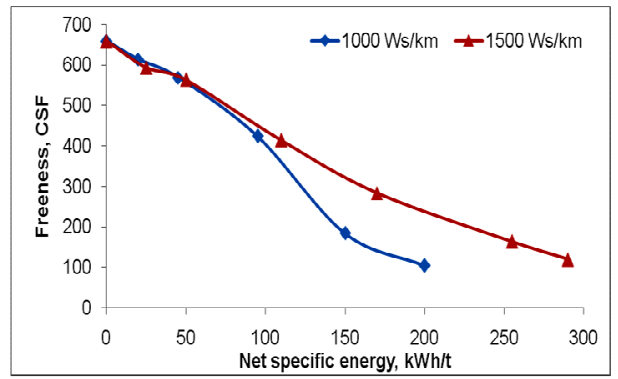

Figure 1: Evolution of freeness with pulp refining

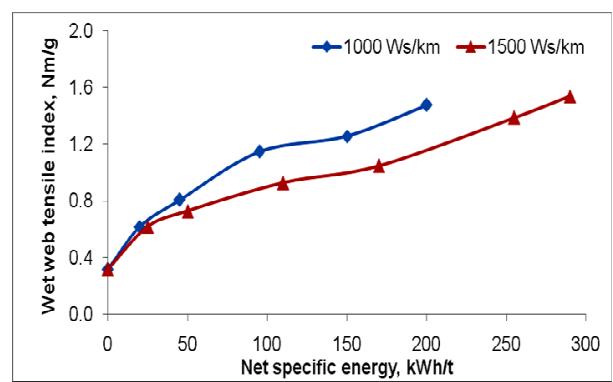

Figure 2: Evolution of wet web tensile index with pulp refining

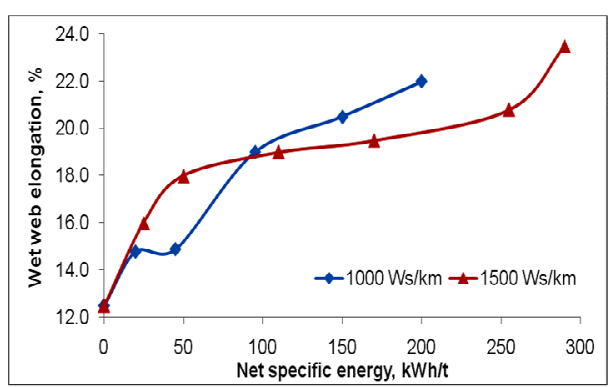

Figure 3: Evolution of wet web elongation with pulp refining 


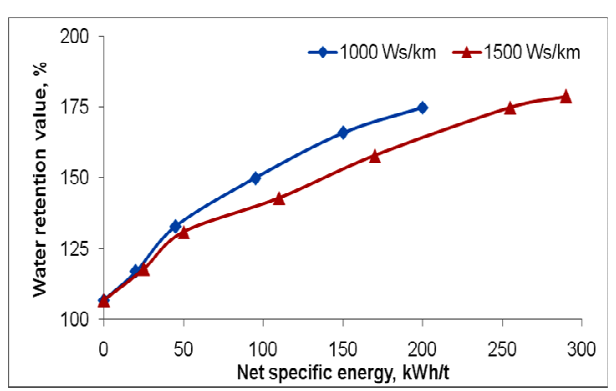

Figure 4: Evolution of water retention value with pulp refining

The strength of the wet web, its tensile strength and elongation are determined by fiberfiber interactions and the presence of curl and micro-compressions in the fibers. It is only when the fiber-fiber interaction is high that the extensibility potential of the fibers provided by the curl and micro-compressions can be fully utilised. ${ }^{36}$

The water retention value, defined as the ratio of water remaining in the pulp to dry fiber weight after centrifugation of a fiber pad under standard conditions, is used as a measure of fiber swelling and provides useful information on the dewatering performance of pulps on paper machines. ${ }^{37}$ Fiber swelling accompanied by fibrillation and an increase in fiber flexibility is important in developing fiber-fiber bonding in paper. ${ }^{38}$ The contribution of water to the beating mechanism of fibrous pulp has been well described by Przybysz et al. ${ }^{39}$ who reported that the highest increase in internal fibrillation was observed for the pulp samples refined in water, in comparison with different alcohols, such as methanol, ethanol, n-propanol and n-butanol, because of the higher dipole moment of water than those of the alcohols. The papermaking potential of the beaten fibrous pulp is increased by the growth of total free energy from the bonds connecting cellulose fibers, which, in turn, depends on the specific energy of these bonds, the bonded area between the fibers in paper, its structure and the flexibility of fibers. ${ }^{39}$ The breaking of bonds between the structural and morphological elements of the cellulose fibers is the essence and purpose of refining. The amount of internal fibrillation is measured by the changes in water retention values (WRV) during cellulose pulp refining. ${ }^{40}$ The bonding ability of a pulp is related to the degree of swelling, which is measured as the water retention value. Several changes in fiber structure influence this property,

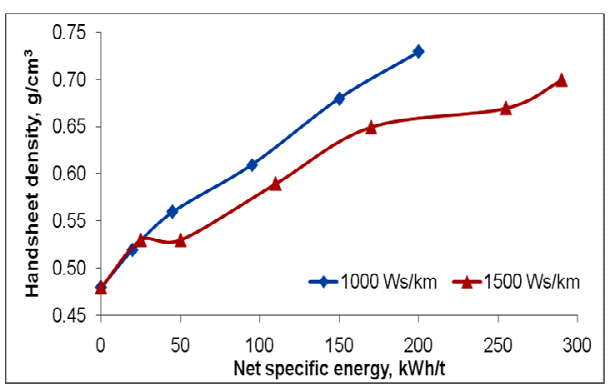

Figure 5: Evolution of handsheet density with pulp refining

such as the swelling of the fiber wall, external fibrillation and creation of fines.

The water retention value of the pulp refined at $1000 \mathrm{Ws} / \mathrm{km}$ specific edge load was comparatively higher than that of the pulp refined at $1500 \mathrm{Ws} / \mathrm{km}$ specific edge load at any net specific energy level (Fig. 4). The figure shows that the bamboo pulp refined at $1000 \mathrm{Ws} / \mathrm{km}$ specific edge load required much less refining energy than the pulp refined at $1500 \mathrm{Ws} / \mathrm{km}$ specific edge load to reach a target water retention value. The results are in agreement with the previous study of Zhao et al., who reported that refining bamboo kraft pulp with the specific edge length of $1.12 \mathrm{~km} / \mathrm{s}$ gave more gentle refining and slower water retention value development, in comparison with refining at the specific edge length of $2.92 \mathrm{~km} / \mathrm{s}$. Therefore, the applied specific edge load can influence the water retention value of pulp.

The wet web tensile index, wet web elongation and water retention of the pulp at $660 \mathrm{~mL} \mathrm{CSF}$ increased from the initial values of $0.32 \mathrm{Nm} / \mathrm{g}$, $12.5 \%$ and $107 \%$, respectively, to $1.15 \mathrm{Nm} / \mathrm{g}$, $19 \%$ and $150 \%$, respectively, for the pulp of 420 $\pm 5 \mathrm{~mL} \mathrm{CSF}$ refined at $1000 \mathrm{Ws} / \mathrm{km}$, compared to the corresponding values of $0.93 \mathrm{Nm} / \mathrm{g}, 19 \%$ and $143 \%$, respectively, for the pulp refined at 1500 $\mathrm{Ws} / \mathrm{km}$.

\section{Comparison of dry strength properties}

Figure 5 illustrates the development of handsheet density plotted against the net specific energy for the pulp refined at 1000 and 1500 $\mathrm{Ws} / \mathrm{km}$ specific edge loads. The handsheet density was higher when the pulp was refined at 1000 $\mathrm{Ws} / \mathrm{km}$ specific edge load, compared to 1500 $\mathrm{Ws} / \mathrm{km}$ specific edge load. Refining at 1000 $\mathrm{Ws} / \mathrm{km}$ specific edge load produced a denser sheet than refining at $1500 \mathrm{Ws} / \mathrm{km}$ specific edge load at any net specific energy level. This is due to higher 
internal fibrillation in lower intensity refining, leading to higher levels of fiber collapsibility and conformability. A similar finding was reported by Subrahmanyam et al., where pulp strength could be improved by low specific edge load refining, without decreasing the pulp drainage.

Bonding ability is quite well indicated by the tensile strength, which clearly increases with an increase in refining energy for the pulp refined at both specific edge loads (Fig. 6). However, at higher net specific energy, of about $150 \mathrm{kWh} / \mathrm{t}$, the rate of increase in tensile strength decreased, probably indicating the cutting effect on fibers. It was found that lower intensity refining increased net energy efficiency. When applying $290 \mathrm{kWh} / \mathrm{t}$ net specific energy at $1500 \mathrm{Ws} / \mathrm{km}$ specific edge load, a tensile index of $70.0 \mathrm{Nm} / \mathrm{g}$ was recorded. When the intensity was reduced to $1000 \mathrm{Ws} / \mathrm{km}$ specific edge load, the tensile index of $71.0 \mathrm{Nm} / \mathrm{g}$ was developed, applying $150 \mathrm{kWh} / \mathrm{t}$ net specific energy (Fig. 6).

The evolution of tensile strength with the change in pulp freeness is also reflected in Figure 7. The tensile index was higher when the pulp was refined at $1000 \mathrm{Ws} / \mathrm{km}$ specific edge load,

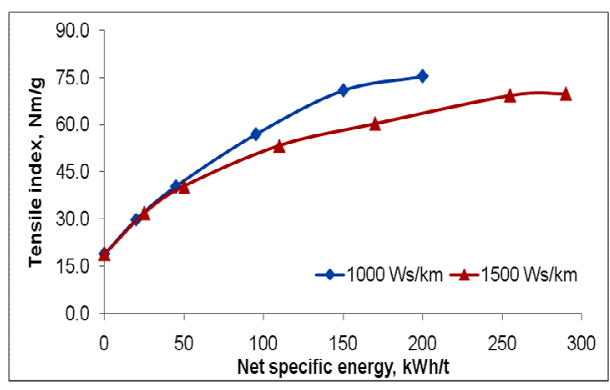

Figure 6: Evolution of tensile index with pulp refining



Figure 8: Effect of water retention value on tensile index compared to that refined at $1500 \mathrm{Ws} / \mathrm{km}$ specific edge load. Refining at $1500 \mathrm{Ws} / \mathrm{km}$ specific edge load produced lower tensile development versus freeness loss. Refining at $1500 \mathrm{Ws} / \mathrm{km}$ specific edge load increased the tensile index to 53.5 $\mathrm{Nm} / \mathrm{g}$ at $415 \mathrm{~mL} \mathrm{CSF}$, while at $425 \mathrm{~mL} \mathrm{CSF}$, refining at $1000 \mathrm{Ws} / \mathrm{km}$ specific edge load produced a tensile index of $57 \mathrm{Nm} / \mathrm{g}$. There exists a linear correlation between the water retention value and the tensile strength of paper, which supports previous findings, ${ }^{41}$ for different pulps. The relation between the tensile index and the water retention value is shown in Figure 8.

The bursting strength of paper depends primarily on fiber strength and bonding strength. The increase in bursting strength was at a higher rate during refining up to the net specific energy level of $150 \mathrm{kWh} / \mathrm{t}$, beyond which this rate of increase was lower, indicating that further refining did not have any significant effect on the bursting strength of paper (Fig. 9). The bursting strength development is relatively lower for the bamboo pulp refined at $1000 \mathrm{Ws} / \mathrm{km}$, compared to that refined at $1500 \mathrm{Ws} / \mathrm{km}$ specific edge load.

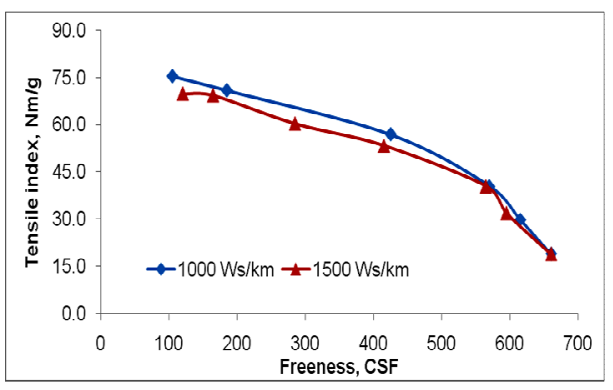

Figure 7: Effect of pulp freeness on tensile index



Figure 9: Evolution of burst index with pulp refining 


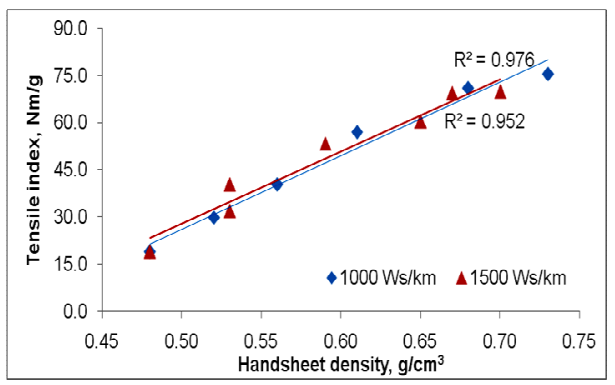

Figure 10: Tensile/density profiles of refined pulp

The results obtained during this study are comparable to previously reported findings by Tripathi et $a .^{21}$ on pulp and papermaking properties of bamboo species Melocanna baccifera. The physical strength properties of handsheets from bleached pulp (88.3\% ISO brightness) refined at $413 \mathrm{~mL}$ CSF were reported to be sufficiently good, i.e. tensile index of 59.7 $\mathrm{Nm} / \mathrm{g}$, burst index of $5.47 \mathrm{kN} . \mathrm{m} / \mathrm{g}$ and tear index of $11.0 \mathrm{mN} . \mathrm{m}^{2} / \mathrm{g}$.

The tensile/density profiles for the pulp refined at the given two specific edge loads are shown in Figure 10. The pulp exhibits similar tensile/density responses. The tensile index development for the pulp refined at $1500 \mathrm{Ws} / \mathrm{km}$ specific edge load was similar to the tensile index development for the pulp refined at $1000 \mathrm{Ws} / \mathrm{km}$ specific edge load at a particular handsheet density. The evolution of tensile index is similar to that reported earlier. ${ }^{18}$ The maximum achievable tearing strength is not significantly different for the two refining intensities

\section{CONCLUSION}

The wet web tensile index, wet web elongation and water retention value of bamboo long fiber fraction pulp increased with refining. In general, the freeness and bulk decreased, whereas the tensile and burst strength increased with increasing net specific energy. Bamboo long fiber fraction pulp responds better to lower intensity refining (1000 Ws/km specific edge load), in terms of pulp strength, decreasing net energy requirements. Significant gains in tensile index at a given freeness level can be gained by refining at lower intensity. There is a huge difference (110 $\mathrm{kWh} / \mathrm{t}$ ) in the specific energy required to reach a given wet web strength at the two SELs, about $210 \mathrm{kWh} / \mathrm{t}$ for $1500 \mathrm{Ws} / \mathrm{km}$, compared with around $110 \mathrm{kWh} / \mathrm{t}$ for $1000 \mathrm{Ws} / \mathrm{km}$. A linear correlation was observed between the water retention value and the tensile strength of paper.
Refining at $1500 \mathrm{Ws} / \mathrm{km}$ has a positive impact on the evolution of bursting strength of paper, as it depends on fiber strength, as well as on bonding strength. Lower intensity refining at higher net specific energy consumption leads to more internal fibrillation and higher bursting strength.

ACKNOWLEDGEMENTS: The laboratory experiments were conducted when the author worked at Central Pulp and Paper Research Institute (CPPRI), Saharanpur, India. The author is thankful to Dr. S.V. Subrahmanyam and Dr. A. G. Kulkarni of CPPRI. The author also thanks the management and staff of CPPRI for their help.

\section{REFERENCES}

1 P. Shanmughavel and K. Francis, Biomass Bioenerg., $\quad \mathbf{1 0}, \quad 383$ (1996), https://doi.org/10.1016/0961-9534(95)00124-7

2 M. D. Fahey, Tappi J., 53, 2050 (1970).

3 K. Ebeling, in Procs. International Symposium on Fundamental Concepts of Refining, September 16-18, Appleton, USA, 1980, pp. 1-33.

D. H. Page, in Trans. $9^{\text {th }}$ Fund. Res. Symp. Fundamentals of Papermaking, MEP, London, 1989, pp. 1-38.

N. K. Bhardwaj, T. D. Duong and K. L. Nguyen, Colloid. Surfaces A, 236, 39 (2004), https://doi.org/10.1016/j.colsurfa.2004.01.024

6 S. Hietanen and K. Ebeling, Pap. Puu, 72, 158 (1990).

7 W. Brecht, Tappi J., 50, 40A (1967).

8 W. Brecht and W. Siewert, Das Papier, 20, 4 (1966).

9 J. E. Levlin, Tappi J., 58, 71 (1975).

10 G. L. Simard and J. Krishnagopalan, Ippta J., 14, 158 (1976).

11 C. F. Baker, Pap. Technol., 39, 27 (1998).

12 P. R. Gupta, in "Nonwood Plant Fiber Pulping Progress Report No. 11", Tappi Press, Atlanta, USA, 1980, pp. 17-24.

13 R. S. Iyengar, in "Nonwood Plant Fiber Pulping Progress Report No. 12”, Tappi Press, Atlanta, USA, 1982, pp. 25-30. 
14 J. Krishnagopalan, N. P. Kutscha and G. L. Simard, Ippta J., 12, 9 (1975).

T. S. Ramadorai, P. M. Trikannad and N. Ravindranathan, in "Nonwood Plant Fiber Pulping Progress Report No. 12”, Tappi Press, Atlanta, USA, 1982, pp. 57-65.

16 T. K. Roy, S. V. Subrahmanyam and R. D. Godiyal, Ippta J., 10, 59 (1998).

J. M. Sarwar, A. Noori, L. Ahsan, D. A. N. Chowdhury and M. A. Quaiyyum, Ippta J., 21, 85 (2009).

18 Y. V. Sood, P. C. Pande, S. Tyagi, I. Payra, Nisha et al., J. Sci. Ind. Res., 64, 299 (2005).

19 S. V. Subrahmanyam, R. D. Godiyal, A. K. Sharma, T. V. Janbade and H. K. Gupta, Ippta J., 12, 11 (2000).

${ }^{20}$ G. Zhao, R. Lai, B. He, T. Greschik and X. Li, BioResources, 5, $1733 \quad$ (2010), https://bioresources.cnr.ncsu.edu/BioRes_05/BioRes_0 5_3_1733_Zhao_LLHG_Replace_SW_Kraft_ECF_Ba mboo_Kraft_Fine_Paper_969.pdf

21 S. K. Tripathi, O. P. Mishra, N. K. Bhardwaj and R. Varadhan, Cellulose Chem. Technol, 5281 (2018), http://www.cellulosechemtechnol.ro/pdf/CCT12(2018)/p.81-88.pdf

22 N. Gurnagul and R. S. Seth, Pulp Pap. Can., 98, 44 (1997),

https://www.researchgate.net/profile/Norayr_Gurnagul /publication/260125133_Wet-

web_strength_of_hardwood_kraft_pulps/links/56b89f9 608ae44bb330d368a/Wet-web-strength-of-hardwoodkraft-pulps.pdf

23 J. Kataja-aho, S. Haavisto, J. Asikainen, S. Hyvärinen and S. Vuoti, BioResources, 7, 1713 (2011), https://bioresources.cnr.ncsu.edu/wpcontent/uploads/2016/06/BioRes_07_2_1713_Katajaah o_HAHV_Infl_Cat_Xylan_Wet_Dry_Strength_Paper_ 2389.pdf

24 J. Kouko, K. Salminen and M. Kurki, Рap. Рuи, 89, 424 (2007).

25 K. Lindqvist and U. B. Mohlin, Tappi J., 65, 119 (1982).
26 H. Lindqvist, K. Salminen, J. Kataja-aho, E. Retulainen, P. Fardim et al., Nordic Pulp Pap. Res. J., 27, 104 (2012), https://doi.org/10.3183/npprj-2012-2701-p104-111

27 P. P. J. Miettinen, P. Kekko and J. Kouko, Nordic Pulp Pap. Res. J., 24, $381 \quad$ (2009), doi: 10.3183/NPPRJ-2009-24-04-p381-387

28 I. I. Pikulik, Pulp Pap. Can., 98, 161 (1997).

29 R. S. Seth, M. C. Barbe, J. C. R. Williams and D. H. Page, Tappi J., 65, 135 (1982).

30 R. S. Seth and M. A. Kingsland, Pulp Pap. Can., 91, 68 (1990)

${ }^{31}$ M. Tchepel, D. Ouellet, D. McDonald, J. Provan, G. Skognes et al., Pulp Pap. Can., 105, 32 (2004), https://www.pulpandpapercanada.com/paptac/PDFs/A pr04/Refining.pdf

32 R. J. Kerekes, in Procs. TAPPI Technology Summit, Atlanta, USA, March 3-7, 2002, pp. 55-66.

33 C. Laine, X. Wang, M. Tenkanen and A. Varhimo, Holzforschung, $\quad \mathbf{5 8}, 233 \quad$ (2005), https://doi.org/10.1515/HF.2004.036.

34 R. P. Kibblewhite, in Trans. $9^{\text {th }}$ Fund. Res. Symp. Fundamentals of Papermaking, Cambridge, U.K., 1989.

35 B. A. Amero, Tappi J., 65, 57 (1982).

36 R. S. Seth, D. H. Page, M. C. Barbe and B. D. Jordan, Svensk Papperstidn., 87, 36 (1984).

37 R. G. LeBel, G. C. Nobleza and R. Paquet, Pulp Pap. Can., 80, 64 (1979).

38 A. A. Brancato, PhD Thesis, Georgia Institute of Technology, 2008.

39 P. Przybysz, M. Kucner, M. Dubowik and K. Przybysz, BioResources, 12, 1737 (2017), https://bioresources.cnr.ncsu.edu/wpcontent/uploads/2017/01/BioRes_12_1_1737_Przybys Z_KDP_Lab_Refining_BSWK_Pulp_Water_Alchols_ Polarity_Swelling_Fiber_Length_10437.pdf

40 P. Przybysz, Ph.D. Dissertation, Lodz University of Technology, Łódź, Poland, 2012.

41 A. Panda, Indian Pulp Pap., July, 63 (1967). 